\title{
Comparison of serum lead level of opium dependent patients with a healthy control group
}

\author{
Gholam Reza Masoomi $^{\circledR}$, Zeinab Rastegar Chupani², Hazhir Heidari Beigvand², Mahdi Rezai ${ }^{3}$, Shahin Dokht \\ Hasan Pour $^{2 *(\mathbb{D}}$
}

${ }^{1}$ Trauma and Injury Research Center, Iran University of Medical Sciences, Tehran, Iran

${ }^{2}$ Emergency Physician, Iran University of Medical Sciences, Tehran, Iran

${ }^{3}$ Emergency Medicine Management Research Center, Iran University of Medical Sciences, Tehran, Iran

\section{Correspondence to:}

Shahin Dokht Hasan Pour, Email: Shahin.Hassanpour2000@gmail. com, Hasanpour.sh@iums.ac.ir

Received: 20 May 2020 Accepted: 9 Aug. 2020 ePublished: 18 Sep. 2020

Keywords: Lead, Abdominal pain Oral opium,

\begin{abstract}
Introduction: The prevalence of multiple symptoms, including mental illness, symptoms that mimic diseases such as pancreatitis, nonspecific abdominal pain and cholecystitis, are high in drug-dependent patients. Objectives: The aim of this study was to consider the clinical signs and serum lead levels of individuals referred to four university hospitals with various complaints.

Patients and Methods: In this study, 128 sample cases in two groups, the case group and control group, have been examined. The case group included 64 persons using oral opium who were suffering from various complaints and referred to emergency department of mentioned hospitals. The control group included 64 patients without any history of addiction.

Results: Mean of blood serum lead level in opium users and control group was $76.34 \pm 17.82 \mathrm{mg} / \mathrm{dL}$ and $7.68 \pm 3.72 \mathrm{mg} / \mathrm{dL}$ respectively, and the difference between these groups was significantly meaningful $(P<0.001)$. The most prevalent complaints were abdominal pain and pulmonary complaints.

Conclusion: Findings of the current study showed high levels for an average serum lead level for oral opium addicts among the studied statistical population. In addition, results show that ultimate diagnosis of lead poisoning is a factor justifying symptoms for addicts with nonspecific symptoms, the subject that confirms several previous reports. This finding asserts the necessity of screening of serum lead level for patients addicted to opium compounds in order to prevent more severe side effects.
\end{abstract}

\begin{abstract}
Citation: Masoomi GR Rastegar Chupani Z, Heidari Beigvand $\mathrm{H}$ Rezai M, Hasan Pour SD Comparison of serum lead level of opium dependent patients with a healthy control group. J Prev Epidemiol. 2020;5(1):e08. doi:10.34172/jpe.2020.08
\end{abstract}

\section{Introduction}

Nowadays, using lead in materials and different industries has caused environmental pollution (1). Regarding the point that main sources of pollution are paint, cosmetics, dust, drinking water, parent's work place, air and food, prevalence of lead contamination is highly probable. While, blood lead concentration has never been globally tested, however prevalence of lead poisoning varied from $8 \%$ to $20 \%$ in different studies (2). Recently, the World Health Organization paid attention to lead poisoning, while lead poisoning affects nervous system, blood, digestion, cardiovascular and renal systems (3).

Recently, frequency of reports on lead poisoning has notably greater than before. These reports are not only limited to a specific area or province but also indicate epidemic lead poisoning among opium users in all provinces of Iran (4).

The fact that most people attended to hospitals having lead poisoning symptoms

\begin{abstract}
Key point
The prevalence of multiple symptoms and nonspecific abdominal pain are high in drug-dependent patients. In this study, 128 sample cases in two groups have been examined. The case group included 64 patients using oral opium who were suffering from various complaints and control group included 64 patients without any history of addiction. Average blood serum lead level was significantly higher in the case group compared to the control group $(P<0.001)$. The most prevalent complaints were abdominal pain and pulmonary obstruction. Mean serum lead levels were high in oral opium addicts.
\end{abstract}

were oral opium users, has definitely supported the idea that this kind of toxicity was mainly because of lead added to opium (5).

Adding lead to opium is highly hazardous and causes serious side effects, death, resulting in irreparable damages for nations as well as acute poisoning $(6,7)$.

Objectives

Considering the frequency of patients with

Copyright $\odot 2020$ The Author(s); Published by Society of Diabetic Nephropathy Prevention. This is an open-access article distributed under the terms of the Creative Commons Attribution License (http://creativecommons.org/licenses/by/4.0), which permits unrestricted use, distribution, and reproduction in any medium, provided the original work is properly cited. 
different complaints including headache, non-specific abdominal pain, constipation, irritability and memory disorders among the Iranian population, this research aims to study clinical symptoms and blood lead level (BLL) of individuals referring to Rasul Akram, FiroozAbadi, Firoozgar, and Haft-e-Tir hospitals.

\section{Patients and Method}

In this case-control study, 128 sample cases in two groups, the case group and control group, have been examined. Sixty-four patients using oral opium who were suffering from various complaints and referring to emergency department of our hospitals were examined and then their serum lead level was assessed. Control group included 64 healthy individuals, while none of them were sick and were matched regarding age and gender with the first group. Their serum lead level along with other variables were also assessed.

Using checklists, information related to two groups including demographic information, health condition and life style was gathered. After completion of checklists, data were analyzed as per research purpose.

\section{Ethical issues}

Human rights were respected in accordance with the Helsinki Declaration 1975, as revised in 1983. The ethical committee of Iran University of Medical Sciences (Ethical code\# IR.IUMS.FMD.REC1396.94113070121) approved the study. The informed consent was taken from the patients as well as from parents and first relatives. This paper was extracted an original research from the Ph.D., thesis in emergency medicine of Shahin Dokht Hasan Pour (Thesis \#4981) in Iran University of Medical Sciences Faculty of Medical (Emergency Department).

\section{Statistical analysis}

The data were analyzed by IBM SPSS 23 statistical package (SPSS Inc, Chicago, and IL.USA). Results were analyzed using descriptive statistics methods, frequencies, cumulative frequency percentage and charts. To analyze the data, $t$ test, one-way analysis of variance (ANOVA) and chi-square were applied. The correlation between BLL and drug consumption was investigated by regression analysis.

\section{Results}

Case group included 64 participants from 29 to 77 years old with average age of $46.27 \pm 9.12$ years old. Among them $97 \%$ were men. The most significant complaint was abdominal pain and intestinal obstruction. All cases went under endoscopy and colonoscopy.

Other symptoms of patients were; decreased appetite, chronic constipation, nausea and vomiting, memory disorder, anemia, finger paresthesia, weakness and fatigue, weight loss, bone and muscular pain. Diagnostic sonography results were normal for all cases however; four cases had gallbladder stone and sludge. Two cases underwent laparotomy, although final diagnosis for them has been ileus. Among 33 patients suffering from abdominal pain and $71.28 \%$ had anemia. Liver enzymes were elevated in $32.41 \%$ of cases. Renal function was normal for all cases.

Serum lead levels were 41 to $105 \mathrm{mg} / \mathrm{dL}$ with average of $76.34 \pm 17.82 \mathrm{mg} / \mathrm{dL}$ for case group and 3 to $18 \mathrm{mg} / \mathrm{dL}$ with average of $7.68 \pm 3.72 \mathrm{mg} / \mathrm{dL}$ for control group. Average blood serum lead level was significantly higher in the case group compared to the control group $(P<0.001)$.

Oral opium users' lead level in symptomatic patients is shown in Figure 1. Serum lead level for all patients in the case group who admitted with specific symptoms was higher than $25 \mathrm{mg} / \mathrm{dL}$ (toxic), Serum lead level for 70.96\% patients with non- specific symptoms was higher than $25 \mathrm{mg} / \mathrm{dL}$ (toxic), And in control group serum lead level was below $25 \mathrm{mg} / \mathrm{dL}$ for all cases. There is a significant difference in ranges of serum lead levels in the three groups $(P<0.05$; Table 1$)$

Daily oral opium consumption in individuals under 50 years old was $1-3 \mathrm{~g}$ with mean of $1.73 \pm 0.23 \mathrm{~g}$. On the other hand, for those aged more than 50 years old, 2-4 grams of daily consumption with average use of $2.89 \pm 0.27$ $\mathrm{g}$ was reported. There was a significant relationship between serum lead level and quantity of narcotic utilization in the case group, which indicates serum lead level has significantly increased as drug use has increased $(P=0.032)$.

The duration of oral opium use in the case group was from five months to 30 years with average time of 15.24 years. For the case group, no significant relationship between serum lead level and the duration of utilization was detected $(P=0.213$; Figure 2$)$.

\section{Discussion}

Lead toxicity has been recognized for thousands of years and still exists today. Lead as a heavy metal can act as an acute or chronic toxicity cause.

Inorganic lead is absorbed through the lung and gastrointestinal tract and then gets accumulated in blood, soft tissues and bone. Clinical symptoms and signs of lead

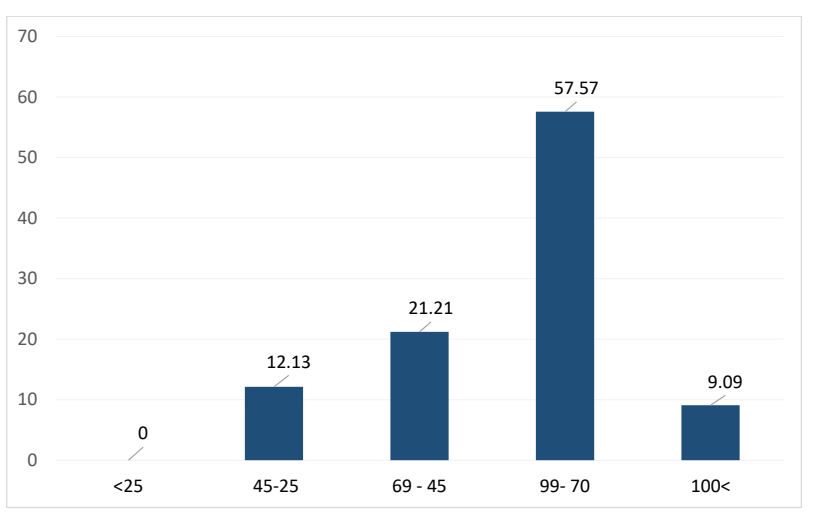

Figure 1. Serum lead level frequency percent for oral opium addicts. 
Table 1. Serum lead level for patients

\begin{tabular}{|c|c|c|c|c|}
\hline \multirow[b]{2}{*}{ Lead level (mg/dL) } & \multicolumn{4}{|c|}{ Frequency percent } \\
\hline & $\begin{array}{l}\text { Patients referring with dominant } \\
\text { symptoms }\end{array}$ & $\begin{array}{l}\text { Patients referring with non-dominant } \\
\text { symptoms }\end{array}$ & Control group & $P$ Value \\
\hline$<25$ & 0.00 & 29.04 & 100 & 0.016 \\
\hline $25-45$ & 12.13 & 41.95 & 0 & 0.029 \\
\hline $45-69$ & 21.21 & 19.35 & 0 & 0.041 \\
\hline $70-99$ & 57.57 & 9.66 & 0 & 0.003 \\
\hline$>100$ & 9.09 & 0 & 0 & $<0.001$ \\
\hline
\end{tabular}

poisoning vary from patient to patient. Lead poisoning influences central and peripheral nervous systems, kidneys performance, vascular system and digestive system and causes anemia, kidney failure, neuropathy and digestive symptoms (12).

Masudi et al reported three cases of lead poisoning in drug dependent people and therefore presented it as a new source of lead poisoning in Iran (8).

Addiction and its corresponding socioeconomic consequences is one of the most important problems in countries such as Iran. Several studies have reported lead poisoning for addicts. In addition, lead poisoning in drugdependent patients has been observed before; e.g., Algora et al reported some instances of lead poisoning in addicts who referred to hospitals with abdominal pain and anemia (9).

Beattie et al reported 5 cases of lead and drug injection (10). Antonini et al explained a case of lead poisoning in heroin addicts (11). Lead traces in drugs has also been reported in the study by Aghaee et al (12). They showed that drug dealers and smugglers may use lead as an additive to drug during production which helps them to enhance weight and gain in more benefit. Thus drug is known as a potential source for lead poisoning. In this study, patients' BLL was higher than the control group which indicated a significantly meaningful difference between the two mentioned groups. Moreover, patients' BLL for drug addicts was correlated with amount of drug consumption. Both groups were matched and they only differed in oral

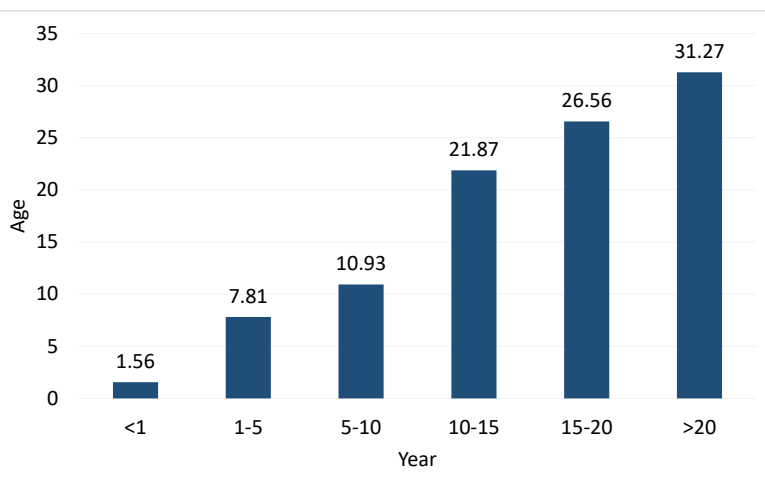

Figure 2. Duration of opium using for case group. drug use; therefore, BLL increases can be as a result of drug contamination with lead. All persons had toxic levels of lead which were equivalent to $25 \mathrm{mg} / \mathrm{dL}$ and more (8).

On the other hand, the prevalence of various symptoms including mental diseases, symptoms that imitate diseases such as cholecystitis, pancreatitis, and non-specific abdominal pains are high in drug addicts (13-15).

Soltaninejad et al (2011) evaluated 25 patients seen from 2002 to 2007 with lead poisoning in the Loghman Hakim hospital poison center, Tehran, Iran. Seven of the patients had a history of opium addiction as the only probable source of lead poisoning, and none of them had occupations known to involve exposure to lead. The average age of these patients was $38.7 \pm 9.3$ years. The average BLL in these patients was $109 \pm 37.6 \mathrm{mg} / \mathrm{dL}$ Lead poisoning should be considered in patients with a history of opium abuse who present with non-specific clinical manifestations.

Wolf's study presented drugs as a potential source for lead poisoning. Patients' BLL was higher than control group which was statistically significant. In addition, there was a relationship between drug-dependent patients' BLL and drug use. Two groups were matched and the only differed in oral drug use respect, therefore BLL elevation in case group can be due to drug poisoning by lead. Around $40 \%$ of patients' lead level was toxic which is equivalent to $25 \mathrm{mg} / \mathrm{dL}$ and more (13).

Considering the research findings of Anderson's study, it seems that high BLL level can justify these findings for drug addicts. Hence, screening of serum lead concentrations in drug addicts, especially for those with non-specific complaints, can be useful. There was not any specific relationship between BLL and duration of drug abuse in the case group, which is expected by considering half-life of 36 days of lead and duration of drug use in individuals (at least 2 years) (15).

In moderate and chronic cases, involvement of central nervous system and symptoms associated with nephropathy have been reported by Lochitch (17). For adults, BLL elevation in mainly because of occupational contacts (18). Thanks to higher levels of workplace safety during recent years, occupational lead poisoning has decreased among adults in the world and new forms of non-occupational poisoning have emerged (19). New type of lead poisoning 
resulting from opium use which is polluted with lead is gradually emerging in our region (20). Drug addiction and addiction patterns are turning into high risk methods and drugs. Drug suppliers and users may add lead for increasing the weight and for opportunistic reasons during the drug preparation process. Moreover, several cases of pathologic findings like neuropathy, abdominal pain and anemia have been observed for opiate addicts (21).

\section{Conclusion}

Findings of the current study suggested high levels of serum lead level for oral opium addicts among the studied statistical population. In addition, results show that ultimate diagnosis of lead poisoning is a factor justifying symptoms for addicts with specific symptoms, the finding that confirms several previous reports. This finding asserts the necessity of screening of serum lead level for patients addicted to opium combinations in order to prevent more severe side effects.

Drug is considered as a potential source for lead poisoning. In this study, patients' serum lead level was higher than the control group which indicated a significantly meaningful difference between two mentioned groups. Moreover, patients' BLL for drug addicts was correlated with amount of drug consumption. Both groups were matched and they only differed in oral drug use, therefore, BLL increase can be due to drug contamination with lead. Based on the results of this study $100 \%$ of oral opium addict individuals with specific symptoms, had toxic levels of lead which was equivalent $25 \mathrm{mg} / \mathrm{dL}$ or more. Thus screening blood lead concentration is a beneficial point for addicts especially those who have non-specific complaints.

\section{Recommendations}

- Considering the point that, costs and consequences of lead poisoning can be totally prevented through reduction and elimination of exposing lead and early diagnosis of high levels of lead in the blood. Clinicians of primary care should play an active role in prevention and early diagnosis of individuals who are exposed to lead.

- Moreover, conducting further research using larger groups of oral/inhaled opium addicts can correspond with more determination and confidence of reports on criteria.

\section{Limitations of the study}

- Non-cooperation of patients for participation in the study and data collection.

- Incomplete data required by the patients.

\section{Authors' contribution}

ShH and GhM designed the study, observed accuracy and validity of the study. $\mathrm{ZH}$ and $\mathrm{HH}$ collected the data and follow the study. ShH, GhM and MR supervised the project. ShH and GhM wrote the paper. All authors edited and revised the final manuscript and accepted its publication.

\section{Conflicts of interest}

The authors declare that they do not have any conflict of interest.

Ethical considerations

Ethical issues (including plagiarism, data fabrication, double publication) have been completely observed by the authors.

\section{Funding/Support}

Iran University of Medical Science supported the study.

\section{Acknowledgements}

The current study was performed by the grant of Iran University of Medical Sciences and with the close cooperation of the authorities, faculty members and colleagues of the hospitals under its supervision and colleagues of Firoozabadi hospital, especially the emergency staff All these participating individuals are highly appreciated.

\section{References}

1. US Department of Health and Human Services. Agency for Toxic Substances and Disease Registry. Toxicological Profile for Lead. Atlanta GA: Public Health Service; 2011. p.587. doi: 10.1016/s0278-6915(97)00090-2.

2. Adult Blood Lead Epidemiology and Surveillance -- - United States, 2002. MMWR Morb Mortal Wkly Rep. 2004;53:578.

3. Saper RB, Kales SN, Paquin J, Burns MJ, Eisenberg DM, Davis RB, Phillips RS. Heavy metal content of ayurvedic herbal medicine products. JAMA. 2004;292:2868-2873. doi: 10.1001/jama.292.23.2868

4. Abdollahi M, Sadeghi A, Jalali N. Lead toxicity of employees of paint factory. Med J Islam Repub Iran. 1996;16:203-206.

5. Farzin L, Amiri M, Shams H. Blood levels of lead, cadmium, and mercury in residents of Tehran biol. Biol Trace Elem Res 2008;123:14-26. doi: 10.1007/s12011-008-8106-y

6. Abdollahi M, Ebrahimimehr M, Nikfar Sh, Jalili N. Monitoring of lead poisoning in simple workers of a copying center by flame atomic absorption spectroscopy. Med J Islam Repub Iran. 1996;10:69-72.

7. Busse FP, Fiedler GM, Leichtle A, Hentschel H, Stumvoll, M. Lead poisoning due to adulterated marijuana in Leipzig. Deutsches Ärzteblatt International. 2008;105(44): 757.

8. Masoodi M, Zali MR, Ehsani-Ardakani MJ, MohammadAlizadeh AH, Aiassofi K, Aghazadeh R, et al. Abdominal pain due to lead-contaminated opium: a new source of inorganic lead poisoning in Iran. Arch Iran Med 2006;9:72-5.

9. Algora M, Martin-Castillo A, Zabala P, Fernandez MN. Lead poisoning due to drug addiction: a new source of poisoning with clinical interest and important epidemiological consequences [in Spanish]. An Med Interna. 1989;6:483-485.

10. Soltaninejad K, Flückiger A, Shadnia S. Opium addiction and lead poisoning. Journal of Substance Use. 2011;16:208-12.

11. Antonini G, Palmieri G, Millefiorini E, Spagnoli LG, Millefiorini M. Lead poisoning during heroin addiction. Ital J Neurol Sci 1989;10:105-8. doi: 10.1007/BF02333882

12. Aghaee-Afshar M, Khazaeli P, Behnam B, Rezazadehkermani M, Ashraf-Ganjooei N. Presence of lead in opium. Arch Iran Med. 2008;11:553-4.

13. Wolf C, Binder R, Barth A, Konnaris C, Rudiger HW. Chronic anemia and abdominal pain as a sequela of lead poisoning [in German]. Dtsch Med Wochenschr. 2001;126:556-8. doi: 10.1055/s-2001-13806

14. Dequanter D, Lefebvre JC, Takieddine M, Belva P, Vaneukem P. An acute pseudo-cholecystitis [in French]. Rev Med Brux. 2001; 22:439-441.

15. Anderson NR, Gama R, Kapadia S. Herbal remedy poisoning presenting with acute abdomen and raised 
urine porphyrins. Ann Clin Biochem. 2001;38:408-10. doi: 10.1258/0004563011900759.

16. Soltaninejad K, Flückiger A, Shadnia S. Opium addiction and lead poisoning. Journal of Substance Use. 2011;16(3):208212.

17. Lochitch G. Perspectives on lead toxicity. Clin Biochem. 1993;26: 371-81. doi: 10.1016/0009-9120(93)90113-k.

18. U.S. Department of Health and Human Services. Agency for Toxic Substances and Disease Registry. Toxicological Profile for Lead. U.S.: Public Health Service; 1999. p. 587.
19. Tandon SK, Chatterjee M, Bhargava A, Shukla V, Bihari V. Lead poisoning in Indian silver refiners. Sci Total Environ. 2001;281:177-82. doi: 10.1016/s0048-9697(01)00845-2.

20. Choy KD, Lee HS, Tan CH. Blood lead monitoring in a decorative ceramic tiles factory in Singapore. Singapore Med J. 2004;45:176-9.

21. Shiri R, Ansari M, Ranta M, Falah-Hassani K. Lead poisoning and recurrent abdominal pain. Ind Health. 2007;45:494-6. doi: 10.2486/indhealth.45.494 